\title{
Leaf Area Index Retrieval Using High Resolution Remote Sensing Data
}

\author{
Michele Rinaldi ${ }^{*}$, Sergio Ruggieri ${ }^{1}$, Pasquale Garofalo ${ }^{1}$, Alessandro Vittorio Vonella ${ }^{1}$, \\ Giuseppe Satalino ${ }^{2}$, Pietro Soldo ${ }^{3}$ \\ ${ }^{1}$ CRA - Unità di Ricerca per i Sistemi Colturali degli Ambienti caldo-aridi \\ Via Celso Ulpiani 5, 70125 Bari, Italy \\ ${ }^{2} I S S I A-C N R$ - Istituto di Studi sui Sistemi Intelligenti per l'Automazione \\ Via Amendola 122 D-I, 70126 Bari, Italy \\ ${ }^{3}$ Consorzio per la Bonifica della Capitanata \\ Corso Roma 2, 71121 Foggia, Italy
}

Received: 21 July 2009. Accepted: 27 November 2009.

\begin{abstract}
Vegetation indices obtained from remote sensed data can be used to characterize crop canopy on a large scale using a non-destructive method. With the recent launch of the IKONOS satellite, very high spatial resolution (1 meter) images are available for the detailed monitoring of ecosystems as well as for precision agriculture.

The aim of this study is to evaluate the accuracy of leaf area index (LAI) retrieval over agricultural area that can be obtained by empirical relationships between different spectral vegetation indices (VI) and LAI measured on three different dates over the spring-summer period of 2008, in the Capitanata plain (Southern Italy).

All the VIs used (NDVI, RDVI, WDVI, MSAVI and GEMI) were related to the LAI through exponential regression functions, either global or crop-dependent. In the first case, LAI was estimated with comparable accuracies for all VIs employed, with a slightly higher accuracy for GEMI, which determination coefficient achieved the value of 0.697. Whereas the LAI regression functions were calculated separately for each crop, the WDVI, GEMI and RDVI vegetation indices provided the highest determination coefficients with values close to 0.90 for wheat and sugar beet, and with values close to 0.70 for tomatoes. A validation of the models was carried out with a selection of independent sampling data. The validation confirmed that WDVI and GEMI were the VIs that provided the highest LAI retrieval accuracies, with RMSE values of about to $1.1 \mathrm{~m}^{2} \mathrm{~m}^{-2}$. The exponential functions, calibrated and validated to calculate LAI from GEMI, were used to derive LAI maps from IKONOS high-resolution remote sensing images with good accuracy. These maps can be used as input variables for crop growth models, obtaining relevant information that can be useful in agricultural management strategies (in particular irrigation and fertilization), as well as in the application of precision farming.
\end{abstract}

Key-words: vegetation index, NDVI, RDVI, GEMI, WDVI, MSAVI, canopy, durum wheat, sugar beet, tomato.

\section{Introduction}

Scientific literature reports a widespread use of remote sensing images acquired in visible, infrared and microwave radiation ranges. These are used in order to obtain information about land use, vegetation status, soil moisture, surface roughness and, in general, to estimate crop and soil information, as well as in applicative studies on plant nutrition, plant protection and precision agriculture (Moran et al., 1997; D’Urso, 2001; Coquil and Bordes, 2005).

The leaf area index (LAI) is a determinant crop factor in mechanisms such as radiation interception and water and energy exchange and it is an important variable for crop growth models. Therefore, accurate measurements of LAI are essential to understand the interaction between crop growth, management and pedo- 
climate condition environment. In addition, LAI is an important biological variable because it represents the area that interacts with solar radiation and it is a measurement of the surface responsible for carbon absorption and gas exchange with the atmosphere. This information is useful in water resource management and for estimation of crop water stress indicators by means of crop simulation models. Indeed, an important application of LAI maps is their assimilation into a Decision Support System to improve the accuracy of crop growth models (Acutis et al., 2010).

Ecosystem models, usually applying large spatial scales, require a great number of in-situ LAI measurements or simulated LAI in their set-up. The possibility of estimating spatially distributed LAI from remotely sensed data is therefore an application of great interest (Running et al., 1999; Dente et al., 2008). LAI can be derived from remote sensed data mainly by applying empirical models, i.e. statistical relationships built on remote sensing vegetation indices (VI) and LAI ground measurements. The main underlying issue in the use of VIs is their potential lack of generalisation of empirical relationships, which, when established with a specific dataset, will not necessarily give good results for other situations. On the other hand, on specific sites and using high resolution remote sensed data, these methods can give accurate LAI estimates.

A number of different VI was been developed by various authors in order to improve the sensibility of the indices to the parameter which has to be obtained, while minimising the interference of external factors such as soil background, conditions of illumination and observation and atmospheric diffusion.

Efforts are currently in progress to improve the simulation performances of distributed models with the assimilation of LAI derived from VI calculated by means of remote sensing information, usually via Normalized Difference Vegetation Index (NDVI) (Acutis et al., 2008; Dente et al., 2006 and 2008; Jarlan et al., 2008; Gigante et al., 2007).

The aim of this study is the evaluation of LAI estimates that can be obtained by empirical relationships between vegetation indices calculated from high resolution satellite data and measured leaf area index, for identifying which is the VI that can provide the best results.

\section{Materials and methods}

\subsection{Ground measurements}

Field measurements were carried out in 2008 in the Capitanata plain (Fig. 1), located in the northern part of the Apulia region (Southern Italy). The most widespread crops are winter wheat (rainfed), sugar beet, tomato, vegetables, grapevine and olive orchards. A large flat area (about $150 \mathrm{~km}^{2}$ ) was surveyed in May, June and July, when three IKONOS images were acquired. The parameters of crop type, LAI, green canopy cover percentage, plant height and phenological stages were all monitored as the satellite passed overhead. Ground truth measurements were collected together with images of different crop types at different growth stages and under various soil types.

A total of 105 fields were surveyed (mainly sugar beet, tomato and durum wheat) (Tab. 1). Agricultural fields were chosen for their yield conditions and on the basis that they were large enough (greater than 2 ha) to link field-averaged measurements with field-averaged remote sensed observations through Global Positioning System (GPS) data. A Garmin GPS 76 model receiver with 12 parallel channels continuously tracked the area and used up to 12 satellites to compute and update positions. Acquisition times were approximately 15 seconds in warm conditions and approximately 45 seconds in cold conditions, with position accuracy less than 15 meters.

\subsection{Leaf Area Index}

Leaf area index is defined as the total one-sided leaf area per unit ground surface area (i.e., $\mathrm{m}^{2}$ $\mathrm{m}^{-2}$ ). LAI was measured with LAI-2000 Plant Canopy Analyzer (LI-COR, 1992 Lincoln, NE,

Table 1. Numbers of fields monitored in 2008 study during the three satellite passes, distinguished by different crops; the numbers in brackets indicate measurements used to validate relationships.

\begin{tabular}{lrrrcc}
\hline & $9^{\text {th }}$ May & $2^{\text {th }}$ June & $8^{\text {th }}$ July & Total \\
\hline Durum wheat & $17(5)$ & $2(2)$ & - & 19 \\
Sugar beet & $6(2)$ & $7(2)$ & $5(2)$ & 18 \\
Tomato & 3 & & $13(4)$ & $14(5)$ & 30 \\
Grape wine & 8 & $(2)$ & $5(1)$ & $4(1)$ & 17 \\
Other crops* & 13 & $(3)$ & $5(1)$ & $3(1)$ & 21 \\
\hline All & $47(12)$ & $32(8)$ & $26(9)$ & $105(29)$ \\
\hline
\end{tabular}

* Bare soil, artichoke, potato and asparagus. 


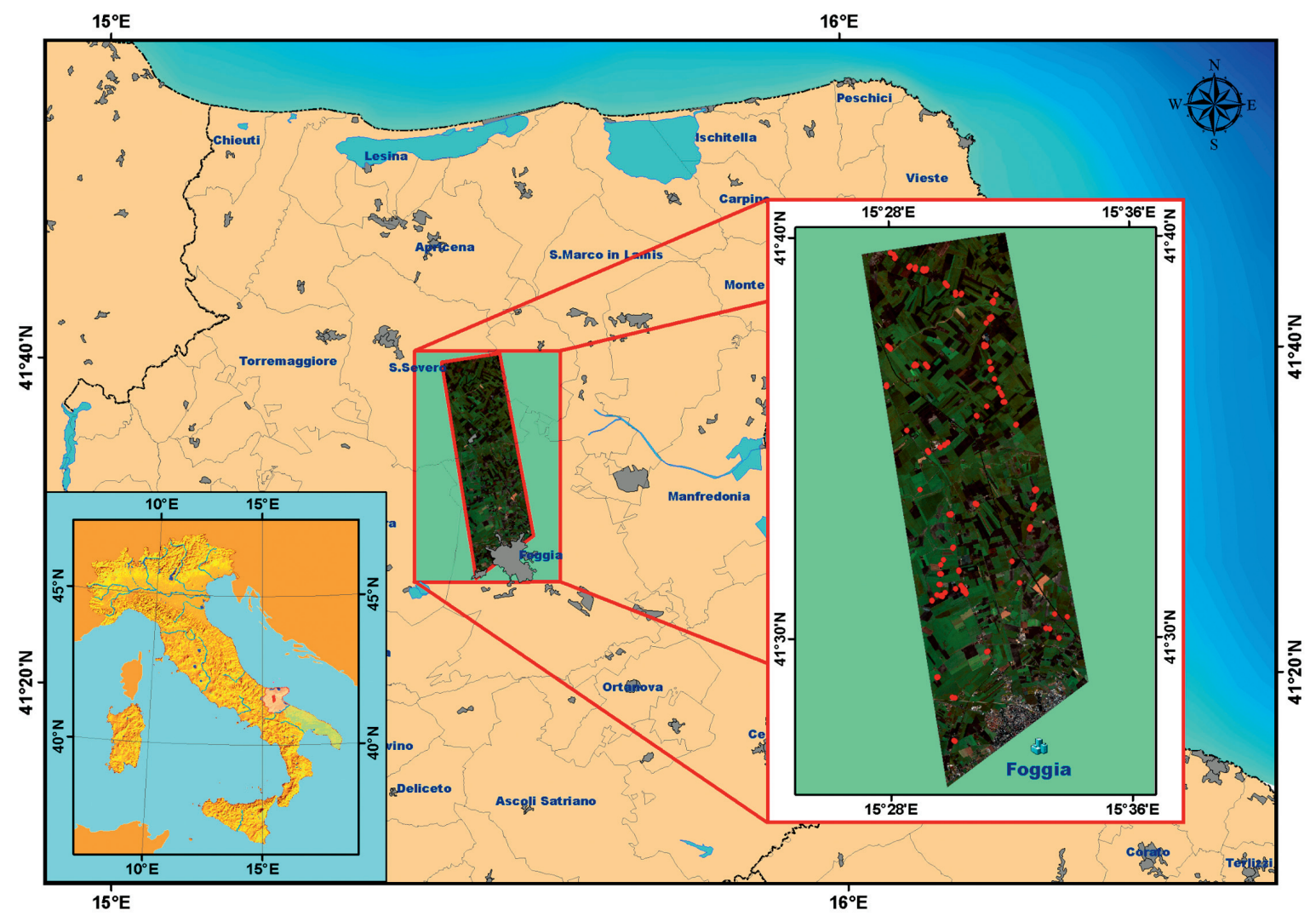

Figure 1. Ground measurement area, with the monitored fields pointed out in red over the IKONOS images.

USA) which uses a fish-eye lens with a hemispheric field of view $\left( \pm 45^{\circ}\right)$. The detector is composed of five concentric rings (sensitive to radiation below $490 \mathrm{~nm}$ ). Each ring responds over a different range of zenith angles and radiation is thus azimuthally integrated.

The measurements were collected in one sensor mode using a $45^{\circ}$ view cap, in clear sky condition, to avoid interferences from users shadow's. For each field, LAI was measured once above the canopy to obtain reference values and six times below the canopy before being averaged out.

\subsection{High resolution images}

IKONOS is a high-resolution commercial earth observation satellite, owned by the Lockheed Martin Corporation. It was launched on September 24, 1999 from Space Launch Complex 6 (SLC-6) at Vandenberg Air Force Base in California. This satellite has a polar, circular, sunsynchronous $681 \mathrm{~km}$ orbit and both sensors have a swath width of $11 \mathrm{~km}$.
The satellite sensor can generate 1 meter panchromatic and 4 meters multiband images with off-nadir viewing of up to $60.25^{\circ}$ for better revisit rate and stereo capabilities. The panchromatic imagery has a spectral wavelength interval ranging from 0.45 to $0.9 \mu \mathrm{m}$ while the multispectral imagery includes four bands in the blue, green, red and near-infrared part of the spectrum (0.45-0.52, 0.52-0.60, 0.63-0.69, and

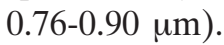

A total of three IKONOS exploitable remote sensing images were acquired during the crop growth season in 2008, with a scene size of about $150 \mathrm{~km}^{2}(25 \times 6 \mathrm{~km})$ (Fig. 1). When multi-temporal data were used, there was the potential for a number of errors due to differences in sun illumination, viewing geometry, and also forth on different acquisition days. To reduce the effects of these factors on VI calculation, IKONOS bands were normalized, converting the Digital Number (DN) into the Top Of Atmosphere (TOA) reflectance by using corresponding calibration coefficients and equations 
(Taylor, 2005). The measurement area lies on a flat surface, so the effects of local surface topography were absent. Moreover, the atmospheric conditions during the acquisition were good, therefore no atmospheric correction method was applied.

\subsection{Vegetation indices}

The biophysical definition of a vegetation index is a quantitative measurement of crop canopy related to plant biomass or vegetative vigour. It is usually calculated from combinations of two or three spectral bands (with red and near-infrared the most common), in order to obtain a single value (index) that is related to the vegetation growth.

In attaining LAI from remote sensing data through the evaluation of VI, agronomic management (plant density, nitrogen fertilization), soil (type, roughness, colour) and atmosphere (fog) are particularly influential factors. Consequently, more than 40 different vegetation indices can be found in literature for remote sensing applications and research (Bannari et al., 1995), some focused on vegetation and plant structure, others taking into account soil reflectance and others considering atmospheric influence. Main agricultural applications of VI are for the estimation of water status, evaporation rates, surface resistance and nitrogen stress, as well as the determination of water stress on regional scales (Nemani and Running, 1989; Nemani et al., 1993).

The vegetation indices and their equations used in this research are shown in Table 2.

2.4.1 Intrinsic indices. The Normalized Difference Vegetation Index (Tucker et al., 1979) was one of the earliest vegetation indices to be widely adopted. NDVI is obtained from bands acquired in the red and near-infrared portions of the spectrum. Reflectance in the red region decreases with the increasing chlorophyll content of the plant canopy, while reflectance in the infrared increases with increasing wet plant biomass. Their normalized differences give a measure of the greenness and vigour of the vegetation.

Renormalized Difference Vegetation (RDVI) is a "hybrid" index, such as the indices proposed by Roujean and Breon (1995). These are supposed to minimize the drawbacks of NDVI in both low and high vegetation coverage. It appears to be more capable of appreciating the long-term evolution of crop canopy or analyzing the spatial variability of heterogeneous or discontinuous canopy covers.

Table 2. Spectral vegetation indices used in LAI retrieval.

\begin{tabular}{|c|c|c|}
\hline Intrinsic indices & & \\
\hline $\begin{array}{l}\text { Normalized difference } \\
\text { vegetation index }\end{array}$ & $N D V I=\frac{(N i r-R e d)}{(N i r+R e d)}$ & \\
\hline $\begin{array}{l}\text { Renormalized difference } \\
\text { vegetation }\end{array}$ & $R D V I=\frac{(\text { Nir }- \text { Red })}{\sqrt{(\text { Nir }+ \text { Red })}}$ & \\
\hline $\begin{array}{l}\text { Indices to reduce the } \\
\text { influence of soil types }\end{array}$ & & \\
\hline $\begin{array}{l}\text { Weighted difference } \\
\text { vegetation index }\end{array}$ & $W D V I=$ Nir $-a \operatorname{Red}$ & $\begin{array}{l}\text { where } \\
a \text { is the slope of the soil line }\end{array}$ \\
\hline $\begin{array}{l}\text { Modified soil adjusted } \\
\text { vegetation index }\end{array}$ & $M S A V I=\frac{(1+L) *(N i r-\operatorname{Red})}{(N i r+\operatorname{Red}+L)}$ & $\begin{array}{l}\text { where } \\
L=1-2 a^{*} N D V I^{*} W D V I \text {, } \\
a \text { and } b \text { are, respectively, the slope and the } \\
\text { intercept of the soil line }\end{array}$ \\
\hline $\begin{array}{l}\text { Indices to reduce } \\
\text { atmospheric effects }\end{array}$ & & \\
\hline $\begin{array}{l}\text { Global Environmental } \\
\text { Monitoring Index }\end{array}$ & $G E M I=\eta\left(1-0.25 \eta .-\frac{(\operatorname{Red}-0.125)}{(1-R)}\right.$ & $\eta=\frac{\left[2\left(\mathrm{Nir}^{2}-\operatorname{Red}^{2}\right)+1.5 \mathrm{Nir}+0.5 \mathrm{Red}\right]}{(\mathrm{Nir}+\operatorname{Red}+0.5)}$ \\
\hline
\end{tabular}

Nir $=$ Near Infrared band spectral reflectance; Red = Red band spectral reflectance . 
2.4.2 Indices to reduce atmospheric effects. The atmospheric effects on vegetation indices are generally radiance dispersion and the absorption of aerosols and water vapour. The dispersion effect is greater in visible bands. However, the degree of absorption is higher in infrared bands. In order to minimize atmospheric effects, a non-linear index called the Global Environmental Monitoring Index (GEMI) was proposed by Pinty and Verstraete (1992).

2.4.3 Indices to reduce the influence of soil types. Some vegetation indices adopt the concept of the soil line, i.e. the relation between visible and infrared reflectance from bare soil that is generally linear, to obtain indices that are better related to the vegetation (Rondeaux et al., 1996). For example, the Weighted difference vegetation index (Clevers and Verhoef, 1993) (WDVI) expresses the distance between red and near-infrared reflectance of vegetation and the soil line. Another index is the Modified Soil Adjusted Vegetation Index (MSAVI) (Baret et al., 1991; Qi et al., 1994). This index reduces soil influence, especially for agricultural crops or homogeneous plant canopy, and improves the sensitivity of the index to the vegetation.

\subsection{Statistical relationships}

LAI (dependent variable) and vegetation indices (independent variables) were analysed with the Procedure REG of SAS/STAT software (SAS, 1987) to evaluate various regression functions by estimating the corresponding regression coefficients and then identifying the regression function with the highest determination coefficients $\left(\mathrm{R}^{2}\right)$. These relationships were calculated separately for durum wheat, sugar beet, tomato, grapevine and other crops.

In literature, various linear and non-linear regression functions have been adopted to relate LAI and VI (Xiao et al., 2008). Often a nonlinear relationship between LAI and VI has been reported (Holben and Justice, 1980; Choudhury, 1987; Qi et al., 2000). For example, Qi et al. (2000) found that a third-order polynomial function of LAI-NDVI and a linear LAI-NDVI relationship both fit well at low vegetation density (LAI < 1.2). However, the difference between the two equations becomes significant at larger LAI where leaves layers overlap themselves and NDVI becomes saturated and insensitive to the changes of LAI.

\subsection{Validation}

From a total of 105 sampling points, 29 were excluded from the analysis and used for the following validation phase. In Table 1 the dates and the crops of the points used to validate the obtained relationships are shown in brackets. In particular, the regression coefficients obtained for all the crops were used to estimate LAI values.

The statistical indices used in the validation phase are described as following. The RMSE (Loague and Green, 1991; Xevi et al., 1996) is defined by

$$
R M S E=\left(\sum_{i=1}^{n}\left(S_{i}-M_{i}\right)^{2} / n\right)^{1 / 2}
$$

where $M_{i}$ and $S_{i}$ are the measured and simulated values, respectively, for the $i$ th data point of $n$ observations.

The coefficient of residual mass (CRM) was used to measure the tendency of the model to overestimate or underestimate the measured values. A negative CRM indicates a tendency of the model toward overestimation (Xevi et al., 1996). The CRM is defined by

$$
C R M=100 *\left(\sum_{i=1}^{n} M_{i}-\sum_{i=1}^{n} S_{i}\right) / \sum_{i=1}^{n} M_{i}
$$

The index of model efficiency (EF) is particularly significant because it allows for the immediate identification of inefficient models. It is upper-bounded by 1 and can assume negative values (lower-bounded at negative infinity). Negative values of EF indicate that the average value of all measured values is a better predictor than the model used.

$$
\mathrm{EF}=\left[\sum_{i=1}^{n}\left(M_{i}-\bar{M}\right)^{2}-\sum_{i=1}^{n}\left(S_{i}-M_{i}\right)^{2}\right] / \sum_{i=1}^{n}\left(M_{i}-\bar{M}\right)^{2}
$$

For graphical representations, the linear regression equation and the 1:1 line of measured vs. simulated values was used.

\section{Results}

From this measurement observation, green canopy cover (\%) and plant height did not show any relationship with VIs; the $\mathrm{R}^{2}$ of linear regression for green canopy cover percentage was 
Table 3. Coefficients and determination coefficients of exponential regressions of LAI vs NDVI and RDVI $\left(\right.$ LAI $\left.=a e^{\text {bVI }}\right)$.

\begin{tabular}{lcccccc}
\hline & \multicolumn{3}{c}{ NDVI } & \multicolumn{3}{c}{ RDVI } \\
\cline { 2 - 7 } & $\mathrm{a}$ & $\mathrm{b}$ & $\mathrm{R}^{2}$ & $\mathrm{a}$ & $\mathrm{b}$ & $\mathrm{R}^{2}$ \\
\hline Durum wheat & 0.3281 & 3.9255 & 0.8624 & 0.3391 & 6.1514 & 0.8925 \\
Sugar beet & 0.3129 & 4.0020 & 0.7854 & 0.3050 & 5.7143 & 0.8977 \\
Tomato & 0.1119 & 6.3954 & 0.6666 & 0.1246 & 9.4801 & 0.6941 \\
Grape wine & 0.1016 & 5.8576 & 0.5176 & 0.1387 & 8.2260 & 0.5175 \\
Other crops* & 0.0524 & 7.9510 & 0.5899 & 0.0654 & 11.4308 & 0.5916 \\
All & 0.1141 & 5.8201 & 0.6825 & 0.1355 & 8.3408 & 0.6946 \\
\hline
\end{tabular}

* Bare soil, artichoke, potato and asparagus.

Table 4. Coefficients and determination coefficients of exponential regressions of LAI vs WDVI and MSAVI $($ LAI $=\mathrm{a}$ $\left.\mathrm{e}^{\mathrm{bVI}}\right)$.

\begin{tabular}{lcccccc}
\hline & \multicolumn{3}{c}{ WDVI } & \multicolumn{3}{c}{ MSAVI } \\
\cline { 2 - 7 } & $\mathrm{a}$ & $\mathrm{b}$ & $\mathrm{R}^{2}$ & $\mathrm{a}$ & $\mathrm{b}$ & $\mathrm{R}^{2}$ \\
\hline Durum wheat & 0.3550 & 9.5314 & 0.9091 & 0.2318 & 4.3276 & 0.7320 \\
Sugar beet & 0.3556 & 7.4654 & 0.9229 & 0.0643 & 6.5791 & 0.6617 \\
Tomato & 0.1384 & 13.9611 & 0.7046 & 0.0655 & 6.0641 & 0.6472 \\
Grape wine & 0.1718 & 11.8237 & 0.5120 & 0.0362 & 6.5740 & 0.5270 \\
Other crops* & 0.0788 & 16.2608 & 0.5776 & 0.0168 & 8.9091 & 0.6847 \\
All & 0.1643 & 11.6017 & 0.6780 & 0.0440 & 6.8753 & 0.6816 \\
\hline
\end{tabular}

* Bare soil, artichoke, potato and asparagus.

significant, but low (0.52) and not significant for plant height $\left(\mathrm{R}^{2}=0.27\right)$.

Two types of VI-LAI relationships are here presented. The first refers to a global regression function, i.e. obtained by adopting measurements carried out for all types of crops. The second refers to specialized relationships for each crop of interest. In both cases, the exponential regression function was used since it gave the best results.

The function parameters and determination coefficients obtained for both, the global and crop-dependent VI-LAI exponential regression functions, are shown in Tables 3,4 and 5. The determination coefficients obtained by changing the VI employed in the global regression functions are comparable and they range from 0.678 to 0.698 . A comparison of the VI for the global regression function showed that the greatest value of $\mathrm{R}^{2}$ was obtained with the GEMI vegetation index (Tab. 5) in agreement with Leprieur et al. (1994). The MSAVI showed values that were not well related to LAI when the VI was higher than 0.6 , with a good fit at LAI values only when lower than $2.0 \mathrm{~m}^{2} \mathrm{~m}^{-2}$ (Fig. 2). The plots in Figure 2 show as LAI reached different saturation values (from 2 of MSAVI $4 \mathrm{~m}^{2}$ $\mathrm{m}^{-2}$ of RDVI) in corrispondence of different
Table 5. Coefficients and determination coefficients of exponential regressions of LAI vs GEMI $\left(\mathrm{LAI}=\mathrm{a} \mathrm{e}^{\mathrm{bVI}}\right)$.

\begin{tabular}{lccc}
\hline & \multicolumn{3}{c}{ GEMI } \\
\cline { 2 - 4 } & $\mathrm{a}$ & $\mathrm{b}$ & $\mathrm{R}^{2}$ \\
\hline Durum wheat & 0.0535 & 6.1517 & 0.8910 \\
Sugar beet & 0.0628 & 5.3429 & 0.9099 \\
Tomato & 0.0075 & 9.1896 & 0.7180 \\
Grape wine & 0.0152 & 7.6637 & 0.5233 \\
Other crops* & 0.0027 & 10.7339 & 0.5907 \\
All & 0.0124 & 8.0045 & 0.6975 \\
\hline
\end{tabular}

* Bare soil, artichoke, potato and asparagus.

threshold values of VI (from 0.3 of WDVI to 0.7 of GEMI). NDVI showed a range of values (from 0.05 to 0.75 ) that was larger than other VIs. In general, for all VIs, a saturation effect is always present when LAI is higher than approximately $3.5 \mathrm{~m}^{2} \mathrm{~m}^{-2}$. This limits the use of these VIs and, as reported in literature, accurate LAI estimates can be obtained only considering the first crop growth phases.

On the other hand, for crop-dependent regression functions, the highest determination coefficients were obtained for durum wheat and sugar beet (with an average of the $5 \mathrm{VI}$ of $\mathrm{R}^{2}=$ 0.857 and $\mathrm{R}^{2}=0.835$, respectively), two crops that covered the soil completely as the satellite passed overhead, confirming previous studies 

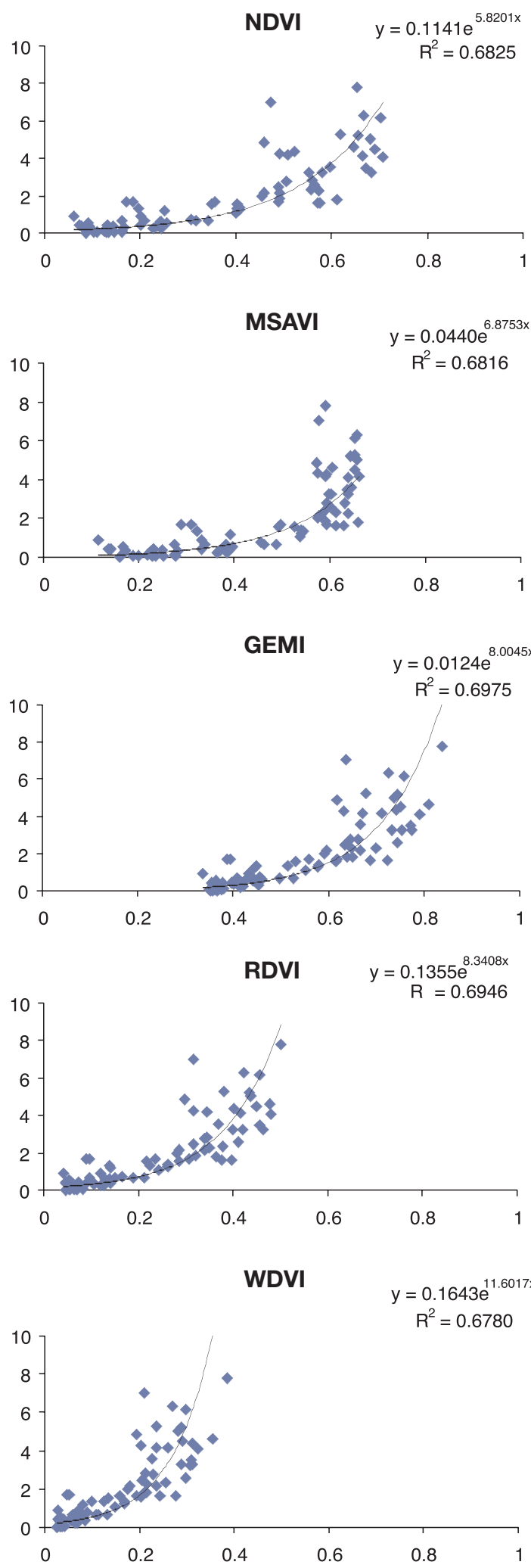

Figure 2. Exponential relationships among vegetation indices ( $\mathrm{x}$ axis) and LAI (y axis, $\mathrm{m}^{2} \mathrm{~m}^{-2}$ ) for all the field crops on the three measurement dates.
(Broge and Leblanc, 2000). The LAI values were well distributed in the range from 0.5 to 6 $\mathrm{m}^{2} \mathrm{~m}^{-2}$. For the tomato crop, which does not cover the soil completely, the average $\mathrm{R}^{2}(0.686)$ was lower than wheat and sugar beet, but still significant. The other crops showed low determination coefficients for the effects of soil types and canopy cover (0.607 for other crops and 0.519 for grapevine).

Comparing the results obtained with the various VIs and considering each crop separately, it appears that the LAI for durum wheat and sugar beet is well correlated with the calculated VI with the exception of the MSAVI index, for which the lowest value was obtained. This occurs because these crops cover the ground completely and the effect of soil is minimized (Fig. 3 and 4). To summarise, for wheat and sugar beet the most correlated VIs were WDVI, RDVI and GEMI with values of $\mathrm{R}^{2}$ close to 0.90 (Tab. 3, 4 and 5).

In literature it is reported that NDVI is very useful in estimating sugar beet foliage cover, but it is only partially sensitive to variations in LAI after complete foliage cover is given, as has been found for wheat (Asrar et al., 1984) and barley (Clevers, 1989). NDVI was related to the LAI of sugar beet with an exponential function in line with Hoffmann and Blomberg (2004). In this research the values found for $a$ and $b$ coefficients are compatible with the values found by the previously cited authors $(\mathrm{a}=0.15, \mathrm{~b}=$ $5.01, \mathrm{R}^{2}=0.80$ for $\mathrm{n}=180$ ). In accordance with the same authors, we can confirm the difficulty of obtaining the LAI from remote sensing images in sugar beet with LAI values greater than $3.5 \mathrm{~m}^{2} \mathrm{~m}^{-2}$.

The relationship obtained for tomato crops provided determination coefficient values close to 0.70 for GEMI, WDVI and RDVI, whereas they were slightly lower for NDVI and MSAVI. This crop, sown in paired rows at a row distance equal to $1.8 \mathrm{~m}$, has a large uncovered soil percentage for long parts of the crop cycle. However, the use of VI taking into account the soil base line (WDWI and MSAVI) did not always improve the relationships. The correlation with other crops was fair, but showed a closer "LAIVI" relationship at low vegetation density (LAI $<2.5 \mathrm{~m}^{2} \mathrm{~m}^{-2}$ ).

The LAI for grapevine was not estimated as efficiently as wheat by remote sensing (also as 

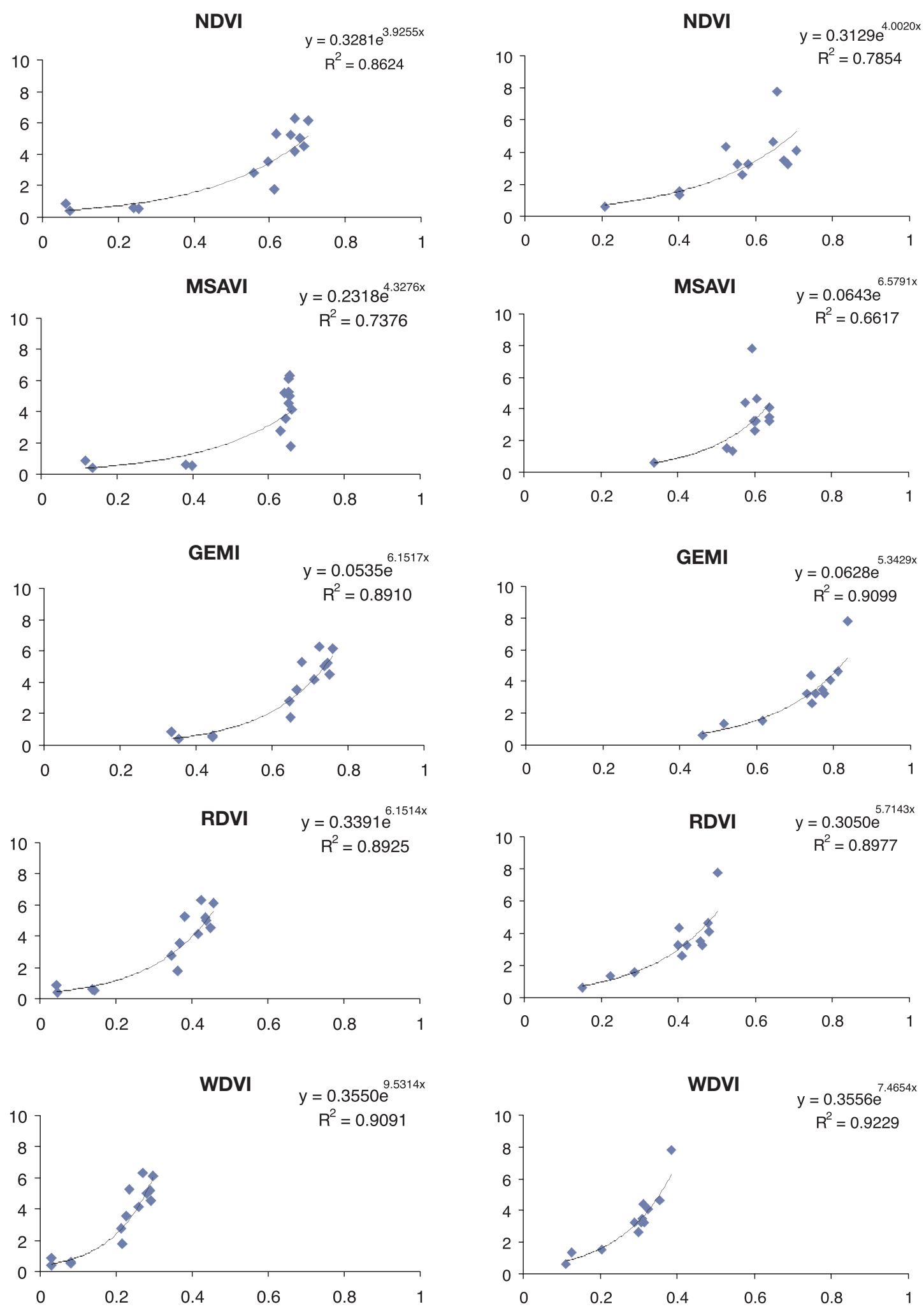

Figure 3. Exponential relationships among vegetation indices ( $\mathrm{x}$ axis) and LAI (y axis, $\mathrm{m}^{2} \mathrm{~m}^{-2}$ ) for durum wheat on the three measurement dates.

Figure 4. Exponential relationships among vegetation indices ( $\mathrm{x}$ axis) and LAI (y axis, $\mathrm{m}^{2} \mathrm{~m}^{-2}$ ) for sugar beet on the three measurement dates. 

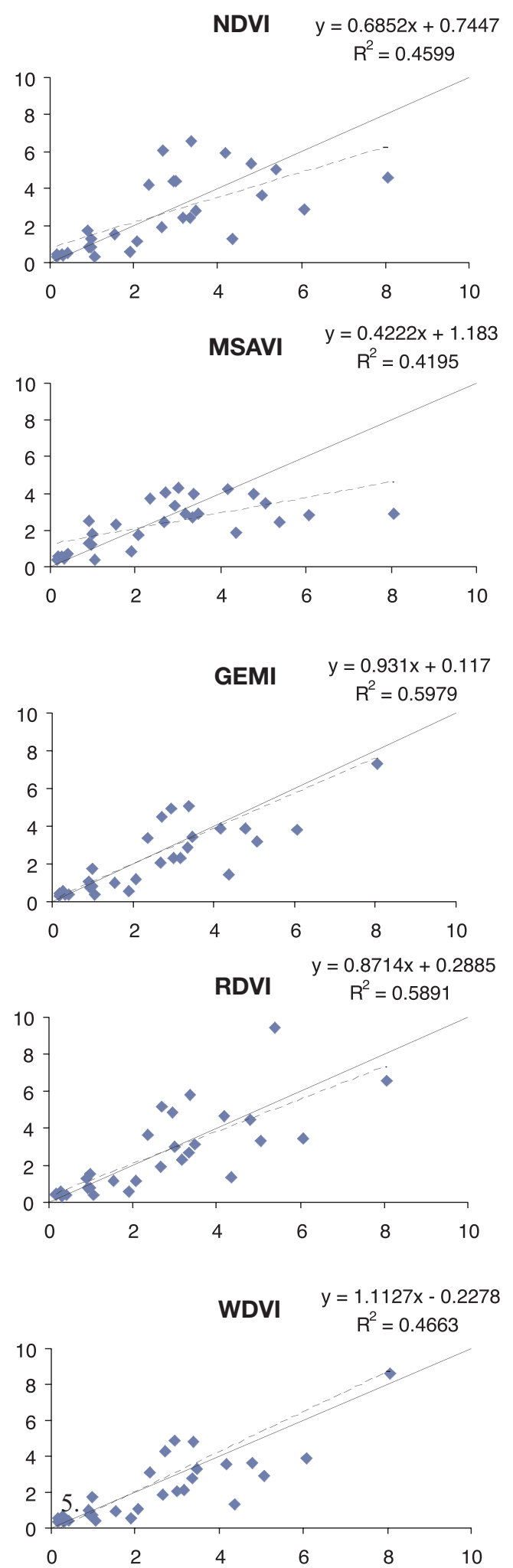

Figure 5. Validation of LAI estimated with different vegetation indices for an independent data set using the relationships reported in Tables 3, 4 and 5. $\mathrm{X}$ axis $=$ measured LAI; y axis = estimated LAI. a result of incomplete soil cover), but showed a good level of accuracy through vegetation indices such as WDVI and MSAVI which usually reduce soil influence.

The validation results are shown in Table 6 and Figure 5. We can generally observe that the average of the predicted LAI underestimates the average of measured LAI (more noticeable for WDVI). On the other hand, WDVI and GEMI indices performed as the best statistical index. In fact, they provided the LAI retrieval with the lower RMSE, approximately equal to $1.1 \mathrm{~m}^{2} \mathrm{~m}^{-2}$. Graphically comparing the measured and estimated LAI values, a slope of regression lines very close to 1 and high regression determination coefficients $\left(\mathrm{R}^{2}\right)$ were obtained by the RDVI, WDVI and GEMI indices (Fig. 5). In general, the validation process can be considered satisfactory for all the vegetation indices, giving LAI estimates which were well in agreement with the measured ones.

As a final step, using the exponential global regression function of LAI vs. GEMI, the LAI values were calculated for each pixel of the scenes of IKONOS images for May, June and July (Fig. 6). According to Satalino et al. (2008), the maps show that over the whole area of the Capitanata plain, the cultivation of wheat is dominant (48\%). In fact, the map of May shows the highest values of LAI; in the maps of June and July, after the durum wheat harvest, LAI values were generally lower. In the map of July (bottom left-hand corner) it is possible to observe some areas with values of LAI in the range of 4-5 $\mathrm{m}^{2} \mathrm{~m}^{-2}$; after accurate analysis, these turned out to be irrigated areas of silagesorghum crop in a large cattle farm.

\section{Conclusions}

The estimation of the canopy leaf area index (LAI) and its spatial distribution is an important source of information derived from remotely sensed data over vegetated areas which can be used to develop approaches for cropland functions and productivity. For example, LAI maps can be used to retrieve crop coefficients to estimate crop water requirements, to evaluate use of soil land, to check irrigated areas and to obtain other important large-scale agronomic information. 
Table 6. Validation results of measured LAI vs estimated LAI with 5 vegetation indices, using an independent data set.

\begin{tabular}{lcccrrr}
\hline & Measured LAI & NDVI & RDVI & MSAVI & WDVI & GEMI \\
\hline Num obs & 29 & 29 & 29 & 29 & 29 & 29 \\
Average & 2.55 & 2.47 & 2.35 & 2.29 & 2.23 & -10.31 \\
Difference \% & & -3.10 & -7.73 & -9.91 & 12.60 & 1.79 \\
STD & 1.92 & 1.95 & 1.84 & 1.30 & 1.49 & 1.13 \\
RMSE $\left(\mathrm{m}^{2} \mathrm{~m}^{-2}\right)$ & & 1.61 & 1.26 & 0.10 & 0.13 & 0.10 \\
CRM & & 0.03 & 0.08 & 0.88 & 0.91 & 0.91 \\
EM & & 0.83 & 0.89 & & & \\
\end{tabular}

STD = standard deviation; RMSE = root mean square error; $\mathrm{CRM}=$ residual mass coefficient; $\mathrm{EF}$ = model efficiency.

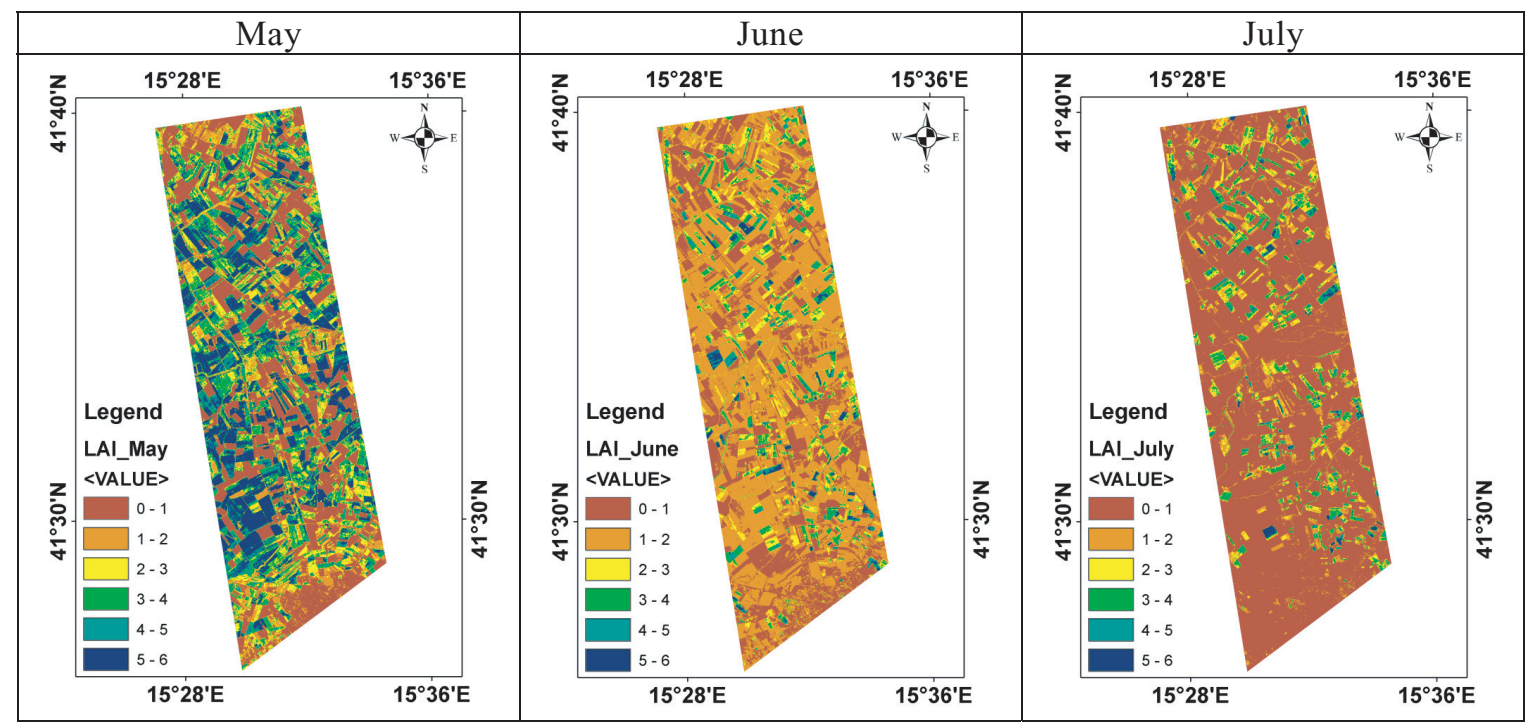

Figure 6. LAI maps derived from the exponential global regression function obtained for GEMI on the three measurement dates.

In this study, exponential regression functions between different VIs extracted from IKONOS high resolution images and LAI were evaluated. The different VIs studied were NDVI, RDVI, WDVI, MSAVI and GEMI using experimental data acquired during the springsummer period of 2008 in the Capitanata plain (Southern Italy). Considering the global regression function obtained by merging the measurements of all the crops surveyed on the experimental site, the best predictor of LAI values was obtained by using the GEMI that provided a determination coefficient equal to 0.697 . Considering the regression functions obtained for each crop separately, the most correlated VIs for wheat and sugar beet were WDVI, RDVI and GEMI with values of $\mathrm{R}^{2}$ close to 0.90 . For tomato, the same VI was again the most correlated with LAI, although with values of $\mathrm{R}^{2}$ close to 0.70 . The LAI for grapevine was not estimated as efficiently as wheat and sugar beet. Validation with independent data-sets confirmed that the higher LAI retrieval accuracies were obtained by using crop dependent regression functions obtained by WDVI and GEMI. In fact, they provided RMSE values of approximately $1.1 \mathrm{~m}^{2} \mathrm{~m}^{-2}$.

Furthermore, it was demonstrated that it is possible to exploit LAI information retrieval from remote sensing at a regional scale, with significant advantages for agricultural applications.

\section{Acknowledgment}

This work is supported by Italian Ministry of Agriculture, Food and Forestry Policies under contract n. 209/7303/05 (AQUATER Project). 


\section{References}

Acutis M., Perego A., Bernardoni E., Rinaldi M. 2010. AQUATER Software as a DSS for Irrigation Management in Semi-Arid Mediterranean Area. Italian Journal of Agronomy, 5, 2:205-215.

Acutis M., Trevisiol P., Perego A., Rinaldi M. 2008. La progettazione di un software per la gestione dei sistemi irrigui. In: Rinaldi M. (ed.): Progetto AQUATER - I Giornata di studio, Bari 31 ottobre 2007, IDEAPRINT, Bari, 163-173.

Asrar G.E., Fuchs M., Kanemasu E.T., Hatfield J.L. 1984. Estimating absorbed photosynthetic radiation and leaf area index from spectral reflectance in wheat. Agron. J., 76:300-306.

Bannari A., Morin D., Bonn F., Huete A.R. 1995. A review of vegetation indices. Remote Sensing Reviews, 13:95-120.

Baret F. and Guyot G. 1991. Potentials and limits of vegetation indices for LAI and PAR assessment. Remote Sens. of Environ., 35:161-173.

Broge N.H., Leblanc E. 2000. Comparing prediction power and stability of broadband and hyperspectral vegetation indices for estimation of green leaf area index and canopy chlorophyll density. Remote Sens. of Environ., 76:156-172.

Choudhury B. 1987. Relationships between vegetation indices, radiation absorption, and net photosyntesis evaluated by a sensitivity analysis. Remote Sens. of Environ., 22:209-233.

Clevers J.G.P.W. and Verhoef W. 1993. LAI estimation by means of the WDVI: a sensitivity analysis with a combined PROSPECT-SAIL model. Remote Sens. of Environ., 7:43-64.

Clevers J.G.P.W. 1989. The application of a weighted infrared-red vegetation index for estimating leaf area index by correcting for soil moisture. Remote Sens. of Environ., 29:25-37.

Coquil B. and Bordes J.P. 2005. FARMSTAR: an efficient decision support tool for near real time crop management from satellite images. Precision agriculture 2005. J.V. Stafford (eds), 873-880.

D'Urso G. 2001. Simulation and management of on-demand irrigation systems: a combined agrohydrological and remote sensing approach. Monography, Wageningen University. ISBN 90-5808-399-3, 174 pp.

Dente L., Rinaldi M., Mattia F., Satalino G. 2006. Assimilation of polarimetric C-Band Radar data into CERES-Wheat model. Rivista Italiana di Telerilevamento, 35:21-34.

Dente L., Satalino G., Mattia F., Rinaldi M. 2008. Assimilation of leaf area index derived from ASAR and MERIS data into CERES-Wheat model to map wheat yield. Remote Sensing of Environment, 112:1395-1407.

Gigante V., Milella P., Iacobellis V., Portoghese I. 2007. Adopting robust NDVI-LAI regressions as a means for improving water balance predictions in Mediterranean regions. Geophysical Research Abstracts, Vol. 9.

Hoffmann C.M. and Blomberg M. 2004. Estimation of Leaf Area Index of Beta vulgaris L. based on optical remote sensing data. J Agronomy \& Crop Science, 190:197-204.

Holben B.N. and Justice C.O. 1980. The topografic effect on spectral response from nadir-pointing sensors. Photogramm. Eng. and Remote Sens., 46:1191-1200.

Jarlan L., Mangiarottia S., Mougina E., Mazzegac P., Hiernauxa P., Le Dantec V. 2008. Assimilation of Spot/Vegetation NDVI data into a Sahelian vegetation dynamics model. Remote Sens. of Environ., 112:1381-1394.

Leprieur C., Verstraete M.M., Pinty B., Chehbouni A. 1994. NOAA/AVHRR Vegetation Indices: Suitability for Monitoring Fractional Vegetation Cover of the Terrestrial Biosphere. Proc. of Physical Measurements and Signatures in Remote Sensing, ISPRS, 1103-1110.

Loague K.M., Green R.E. 1991. Statistical and graphical methods for evaluating solute transport models. J. Contam. Hydrol., 7:51-73.

Moran M.S., Inoue Y., \& Barnes E.M. 1997. Opportunities and limitations for image-based remote sensing in precision crop management. Remote Sens. of Environ. 61:319-346.

Nemani R., Pierce L., Running S.W., \& Band L. 1993. Forest ecosystem processes at the watershed scale: Sensitivity to remotely sensed leaf area index estimates. Int. J. Remote Sens., 14, 13:2519-2534.

Nemani R.R., Running S.W. 1989. Testing a theoretical climate-soil-leaf area hydrological equilibrium of forests using satellite data and ecosystem simulation. Agric. Forest Meteorol., 44:245-260.

Pinty B. and Verstraete M.M. 1992. GEMI: A non-linear index to monitor global vegetation from satellites. Vegetatio, 101:15-20.

Qi J., Chehbouni A., Huete A.R. and Kerr Y.H. 1994. Modified Soil Adjusted Vegetation Index (MSAVI). Remote Sens. of Environ., 48:119-126.

Qi J., Kerr Y.H., Moran M.S., Weltz M., Huete A.R., Sorooshian S. and Bryant R. 2000. Leaf AreaI Index Estimates Using Remotely Sensed Data and BRDF Models in a Semiarid Region. Remote Sens. Environ., 73:18-30.

Rondeaux G., Steven M. and Baret F. 1996. Optimization of soil-adjusted vegetation indices. Remote Sens. of Environ., 55:95-107.

Roujean J.L. and Breon E.M. 1995. Estimating PAR absorbed by vegetation from bidirectional reflectance measurements. Remote Sens. of Environ., 51:375-384.

Running S.W., Collatz G.J., Washburne J., Sorooshian S., Dunne T., Dickinson R.E., Shuttleworth W.J., Vorosmarty C.J., Wood E.F. 1999. Land ecosystems and hydrology. In: King M.D. (ed.): EOS Science Plan. Na- 
tional Aeronautics and Space Administration, Greenbelt, 197-259.

SAS Institute, Inc. 1987. SAS/STAT guide for personal computer: version 6 edition. SAS Institute, Inc., Cary, NC (USA), 400 pp.

Satalino G., Mattia F., Le Toan T., Rinaldi M. 2008. Wheat Crop Mapping by using ASAR AP data. IEEE Transaction on Geoscience and Remote Sensing, 47, 2:527-530.

Taylor M.H. 2005. IKONOS Radiometric Calibration and Performance after 5 Years on Orbit. CALCON Technical Conference, 22-25 August, Logan, UT.
Tucker C.J. 1979. Red and Photographic Infrared Linear Combinations for Monitoring Vegetation. Remote Sens. of Environ. 8:127-150.

Xevi E., Gilley J., Feyen J. 1996. Comparative study of two crop yield simulation models. Agric. Water Manage., 30:155-173.

Xiao Y., Song J., Wang J. 2008. The Temporal Changing Information Extraction on Spectral Reflectance and Growth Parameters of Typical Crops. XXI ISPRS Congress: 3-11 Jul 2008 Beijing, CHINA Commission VII papers, Vol. XXXVII, part B7, 455 p., pdf 42 . 